Journal of Teacher Education for Sustainability, vol. 16, no. 1, pp. 54-75, 2014

\title{
Representation of the Ethiopian Multicultural Society in Secondary Teacher Education Curricula
}

\author{
Robsan Margo Egne \\ University of Oslo, Norway
}

\begin{abstract}
The purpose of this paper is to investigate how the multi-ethnic and multicultural characteristics of the diverse Ethiopian society are incorporated into the current secondary teacher education curricula of the country. To that end, both qualitative and quantitative content analyses were used as tools for data collection. The Ethiopian general national secondary teacher education curricula framework and three other specific secondary teacher education curricula were analysed based on Banks' (1993, 2001, 2006) four approaches to the integration of ethnic and multicultural contents into teacher education curricula. The study exhibited an increasing ambition to address issues of multicultural education into the Ethiopian general national secondary teacher education curricula framework. Nevertheless, elements of multi-ethnic and multicultural education are, to a great extent, missing in the specific secondary teacher education curricula. Implications which are assumed to improve fair representation of the ethnic and cultural diversity of the Ethiopian peoples into the entire secondary teacher education curricula are presented in the article.
\end{abstract}

Keywords: content analysis, multicultural society, representation, secondary education, teacher education curriculum

\section{Introduction}

According to Wagaw (1981), Ethiopia, with its recorded history of at least two and a half millennia, is one of the three oldest nation-states in the world and certainly the oldest in Africa. He adds that, in Ethiopia, many of the problems associated with ethnicity could have been solved long ago, and the country ought to resolve other economic, social and political problems at a higher level. Nonetheless, the core issue that has the most important bearing on both the immediate and the long-term stability of the country depends on how the amalgamation of the different interests, expectations and ambitions of the various ethnic groups are resolved (Wagaw, 1981). Similarly, Semela (2012) states that "the reality in Ethiopia today demands the adoption of democracy and the recognition of both individual and group identities. It calls for more intercultural understanding and respect for people with different racial, ethnic, linguistic, and religious backgrounds" (p. 1). 
Diversity is a fact of life in the Ethiopian society. Based on this premise, one could argue that, as a country in which more than 80 ethno-cultural as well as linguistic groups (Semela, 2014) live together and as a country with a total population of $73,918,505$ (Federal Democratic Republic of Ethiopia Population Census Commission, 2008), it is important for Ethiopia to implement multi-ethnic and multicultural education at all levels of education to make education accessible to its people in a fair way. This is due to the fact that this type of education underpins the assumption that education has a cultural component and is not simply an information transfer (Masemann, 2007).

In attempting to exercise multi-ethnic and multicultural education in Ethiopia, one would expect that teacher education is used as a means to an end. One fairly common rationalisation for addressing multiculturalism in teacher education in general and in pre-service teacher education programme in particular grows out of a recognition that the cultural diversity of a population and the rates of cross-cultural interaction, both domestically and globally, are increasing dramatically. In such growing global interconnectedness, all teacher education programmes, especially pre-service programmes, need to adopt multicultural teacher education as a means of preparing all future teachers to help all children and youth to develop the skills which this type of society and the world require (Garcia \& Pugh, 1992; Sleeter, 2008).

This attempt, amongst other things, may ensure fair representation of multicultural societies in the teacher education curricula, which, in turn, is important for sustainability. In other words, the curricula which ascertain fair representation of multicultural societies are assumed to serve the interests of all groups of people as well as ensure the preservation and sustainability of the cultures, languages, histories, traditional values of all members of society. Concerning this claim, Banks (2010) contends “... the purpose of education is not to eliminate differences but to respond to diversity in ways that enhance all students' growth and development" (p. 358).

It could be argued therefore that the curriculum of teacher education is expected to be responsive to diversity. The curriculum is at the heart of every educational enterprise (Karseth, 2004) and sets up a standard against which educational initiatives are judged (Goodson, 1988). According to Goodson (1988), the written curriculum is an important part of a consolidated state system of schooling; it defines statements of intent and provides clear rules of the game for educators and practitioners, although the ground rules are not prescriptions but parameters. This means, though the written curriculum serves as a guide in the teaching-learning process, there is always a room for entertaining relevant issues in the instruction process. Moreover, Apple and Christian-Smith (1991) assert that texts not only signify how reality is constructed but also influence the creation of knowledge that society has accepted as legitimate and truthful.

Since 1991, Ethiopia has been a federal state, comprised of regional states that are organised on the basis of ethnicity (Hussein, 2008; Semela, 2014; Wagaw, 1999). In relation to this change, a new constitution which states that "the government shall have the duty to support, on the basis of equality, the growth and enrichment of cultures and traditions that are compatible with fundamental rights, human dignity, democratic norms and ideals, and the provisions of the constitution" (Federal Democratic Republic of Ethiopia, 1995, Article 91) was introduced in 1995. In addition, the same constitution underscores "education shall be provided in a manner that is free from any religious influence, political partisanship or cultural prejudices" (Federal Democratic Republic of Ethiopia, 1995, Article 90, p. 133). Similarly, the education and training policy of 
Ethiopia pinpoints “... to provide education that promotes democratic culture, tolerance and peaceful resolutions of differences that raises the sense of discharging societal responsibility” (Federal Democratic Republic Government of Ethiopia, 1994, p. 10). One of the strategies which are expected to facilitate the successful implementation of the reforms is the curriculum. With regard to the curriculum, the education and training policy of Ethiopia states that it is necessary to "ensure that the curriculum developed and textbooks prepared at central and regional levels are based on sound pedagogical and psychological principles and are up to international standards, giving due attention to concrete local conditions and gender issues" (Federal Democratic Republic Government of Ethiopia, 1994, p. 12-13).

This implies that the curricula developed for the various educational levels are expected to address the diverse nature of the Ethiopian society in a reasonable way, apart from entertaining relevant international issues. This, in turn, is expected to contribute to the efforts being made by the Ethiopian government to ensure sustainable development in the country (Egne, 2010; Mergo, 2006, 2010). However, research conducted on issues of diversity (Hussein, 2008; Kenea, 2010; Mergo, 2008; Wagaw, 1999) suggests that the Ethiopian education system is not sensitive to the diverse nature of the country. This, in turn, raises the question whether this is also the case for the secondary teacher education curricula. This makes analysing the current Ethiopian secondary teacher education curricula interesting and timely. According to Harber (1994), Kenyan school textbooks give a high profile to aspects of ethnicity and tribe. What about Ethiopian school textbooks? Overall, this paper is a curiosity-driven study which aims at exploring the extent to which the diversity-oriented policies of the Ethiopian government are transferred and reflected in the national secondary teacher education curricula of the country. In a nutshell, this paper attempts to answer the following key question: How are the multi-ethnic and multicultural characteristics of the diverse Ethiopian society addressed in the current secondary teacher education curricula?

\section{Background and Context: Development of Ethiopian Teacher Education Curricula}

In Ethiopia, formal teacher education started for the first time in 1944 with the launching of a primary school teacher education and training programme in the premise of Menelik II School in Addis Ababa through the assistance of the British Council (Semela, 2014; Wagaw, 1979). Nevertheless, a fully-fledged teachers' training institute was later inaugurated at Gulele in Addis Ababa in 1946/47 (as cited in Semela, 2014). According to Semela (2014), this particular time marks the beginning of a period of reform in the teacher education system of the country.

As stated by (Wagaw, 1979), out of the 32, first batch, prospective teachers who joined the teacher education and training programme at its inception, 24 graduated in 1946. Due to scarcity of trained teachers, the graduates were assigned to teach in different provinces and were also assigned to serve as officers. The two year programme was an effective means of producing qualified teachers. Nonetheless, its capacity was very limited, and it was a slow process. As a result, from 1947, the institute undertook a series of three-month refresher courses for some of the existing elementary school teachers. In the meantime, the Ethiopian Ministry of Education and Fine Arts made summer courses compulsory for all teachers to attend (Wagaw, 1979). 
In general, the launching of formal teacher education in Ethiopia in the mid-1940s marks the beginning of the British influence in the Ethiopian education system (Semela, 2014). However, the British Council withdrew from the project in 1947 after which a Canadian teacher educator named Steinmann was appointed director of the teachers' training institute in the same year (Wagaw, 1979). His arrival marked a new phase for Ethiopian teacher education. The director gradually shifted the teacher education curricula to professional courses. Beginning from 1949, the Ethiopian Ministry of Education and Fine Arts raised the level of the institute's entry requirements and, at the same, time introduced more advanced courses. The central motto of the institute was clearly expressed.

\section{A teacher training institute should be a place where men are trained and men are made. None but the best should be entrusted with the education and care of the children of Ethiopia. Remember that you must be a man yourself before you train a man (Wagaw, 1979, p. 63).}

From the mid-fifties to the mid-sixties, education and training of Ethiopian teachers at all levels was below standard (Bowen, 1976). Though commendable progress was made, there was a long way to go to adequately serve the country. In support of this claim, Semela (2014) states "until the early 1970s, the system had been modestly expanded with the opening of [only] three new TTIs in Harar, Dabre-Berhan, and Jimma Towns" (p. 122). According to Bowen (1976), in 1965, the Division of Secondary Education, under the Ethiopian Ministry of Education, produced the first guidebook on curriculum policies and standards for teacher training institutes. In general, the development of Ethiopian teacher education curricula could be examined in terms of three regimes.

\section{Ethiopian Teacher Education Curriculum during the Haile Selassie Regime}

During the Haile Selassie I regime (1930-1974), Ethiopian pre-service teacher education programmes for government schools followed two patterns depending on the educational level. Elementary teachers were trained at teachers' training institutes whereas secondary teachers were trained at the Faculty of Education, Addis Ababa University (Bowen, 1976). According to Semela (2014), secondary teacher training programme began in a single classroom at the then Haile Selassie I University (now Addis Ababa University) in 1959. However, due to the expansion of modern schools, the programme upgraded first to the Department of Education and then developed the Faculty of Education in 1969. Moreover, Negash (1996) underpins that "under the leadership of Haile Selassie I, who held the portfolio of the Ethiopian Ministry of Education until 1966, the education sector functioned without curriculum guidelines and relevant textbooks" (p. 103).

In general, during the imperial regime, moral education was emphasised and was used as an instrument of nation building underpinned by the cultural and religious values of the ruling class (Semela, Bohl, \& Kleinknecht, 2013). As part and parcel of the overall education system, Ethiopian teacher education curricula used to reflect this moral education during the Haile Selassie I regime. In sum, the curricula during the imperial period were targeted at instilling in the prospective teachers traditional values such as devotion and loyalty to the emperor and to the country, national pride and patriotism. 


\section{Ethiopian Teacher Education Curriculum during the Military or Dergue Regime}

After taking power in 1974, the Dergue regime (1974-1991) introduced a socialistoriented curriculum by leaving aside the cultural values and heritages embodied in the school curriculum during the imperial period. The regime used political education for the nation building project. During the regime, the central foci of the Ethiopian teacher education curricula were imparting communist values, attitudes and world outlook to the prospective teachers because of its strong ties with the Soviet Union, Eastern Germany and some other socialist countries. With regard to this claim, Semela (2014) contends "the military leaders managed to live up to the demands of Soviets and their allies by redesigning the school curricula along the principles of all-rounded socialist personality" (p. 125).

Courses like Marxist-Leninist philosophy and political economy were compulsory subjects in all institutions (Negash, 1990). The general guiding principles of the education system of the country were education for production, social consciousness and scientific inquiry. But, following the fall of the Berlin Wall in 1989, the Dergue government had to reluctantly abandon its communist ideology which subsequently resulted in the elimination of political education from the Ethiopian school curricula (Semela, 2012).

In general, according to Semela (2014), the Ethiopian teacher education system which enjoyed a high prestige as well as status compared to other professions during the Imperial era due to the relative higher salary that teachers used to earn, lost its social acceptance and prestige during the Military government. This is due to the fact that, in contrast to the recruitment policy of the Imperial regime that selected the best and the brightest teacher candidates, the criterion to join the profession dropped to GPA of 0.6 in the Ethiopian School Leaving Certificate Examination during the Military regime. Low teachers' salary combined with loses of social respect has made the teaching profession to be the least preferred among the Ethiopian youth.

\section{Ethiopian Teacher Education Curriculum under the Leadership of the Ethiopian People's Revolutionary Democratic Front}

With the coming to power of the current Ethiopian government or the Ethiopian People's Revolutionary Democratic Front in 1991, all socialist-oriented elements were avoided from the school curriculum and a new education and training policy was formulated in 1994. The current government claimed that the Dergue government did not do justice to the nations, nationalities and peoples of Ethiopia (Semela, 2014), and it envisaged readdressing this situation through formulating a new education and training policy in 1994.

One of the strategies designed to implement the education and training policy was the curriculum. Some of the central tenets of the curricula are promoting democratic principles, respect for human rights, using the Ethiopian nations and nationalities languages as media of instruction until the end of primary education (Federal Democratic Republic Government of Ethiopia, 1994).

In Ethiopia, secondary education is expected to be taught by teachers who have a first degree in their respective disciplines (Federal Democratic Republic Government of Ethiopia, 1994). When it comes to secondary teacher education programme, from 1994 to2002, it was a four-year programme. Nevertheless, with the introduction of a new 
teacher education policy called "Teacher education System Overhaul" (TESO), that initiated a wide-ranging reform in the Ethiopian teacher education sector in 2003 (Ethiopian Ministry of Education, 2003), the secondary teacher education programme was reduced from four years to three years. Again, in 2009, the Ethiopian Ministry of Education replaced TESO with a new secondary teacher education programme entitled "Postgraduate Diploma in Teaching" (PGDT) where prospective teachers undergo professional courses for one year after finishing their undergraduate studies in applied disciplines (Ethiopian Ministry of Education, 2009). The teacher education curricula of this programme entirely focus on professional courses.

In Ethiopia, pre-primary and primary teacher education curricula are usually developed at the respective regional education bureaus. In contrast, secondary teacher education curricula are usually designed at the national level by a team of experts working at the Ethiopian Ministry of Education, subject matter specialists from universities and consultants who prepare an overall curriculum framework for the entire country. The curriculum design is usually done centrally under the guidance of the Ethiopian Ministry of Education. In addition, there is a tradition of preparing modules or study materials that are used across the entire secondary Teacher education Institutions. According to Hussein (2006), the Ethiopian Ministry of Education is guided by the assumption that in addition to ensuring standardised education, modules/study materials ease learning and mastery of knowledge.

On the other hand, he argues that modularised education controls students' minds and makes them see what is presented in the module/study material as a legitimised and highly valued knowledge. This, in turn, implies that, if the Ethiopian education system is to serve the public good, the country's secondary teacher education curricula, more than the other teacher education curricula, are expected to be prepared with great care and in ways that address the diverse nature of the Ethiopian society in a fair manner. These curricula are used across the country's secondary teacher education institutions.

\section{Teacher Education Curriculum and Multicultural Education}

Education is often considered as the best means to instil in the new generation basic humanitarian values such as peace, tolerance and equality (Serbessa, 2006). Drawing on Harber (1994), schools have an important role to play in creating a culture that is more tolerant and trustworthy and less sharply divided along ethnic lines. Of course, there is no consensus among scholars regarding schooling. For instance, according to Apple and Christian (1991), for some people, schooling is seen as a vast engine of democracy-opening horizons, ensuring mobility and so on. For others (Apple \& Christian, 1991), it is seen as a form of social control or, perhaps, as the embodiment of cultural dangers, an institution whose curricula and teaching practises threatens the moral universe of the students who attend it. This paper takes the first stance as its starting point.

The aforementioned fundamental humanitarian values are argued to be comparatively more important in countries characterised by diversity. To address the needs and interests of students coming from such diverse backgrounds, the training of teachers, who are expected to teach those students, is assumed to take into account the experiences and backgrounds of the learners. In so doing, the curricula that are being used in the 
training of prospective teachers are expected to be designed in a way that reflects the students' needs and interests. In line with this notion, Chan (2007) argues that the curriculum may be interpreted as the intersection of the students' home and school cultures.

Multiculturally responsive teaching is often considered as a pedagogical paradigm that enables teachers to utilise students' cultural strengths in his/her teaching (Gay, 2000). This is grounded in the notion that culture and education are strictly intertwined, one being necessary for the continuing existence of the other. Learning is culture dependent. Culture has impacts on identity construction. Supporting this argumentation, Bruner (1996) asserts that learning and thinking are always situated in a cultural setting and always dependent upon the utilisation of cultural resources. According to him, education does not stand alone, and it should not be designed without considering the culture of the beneficiaries.

Moreover, Gagliardi (1995) claims that "different cultures have different learning styles. Adapting teaching to pupils' learning styles can facilitate learning and solve some of the pupils' learning difficulties" (p. 4). Similarly, Schofield (2010) underpins that “ ... students use widely differing styles in classroom discussion and that misunderstanding the cultural context from which students come can lead peers and teachers to misinterpret involvement for belligerence" (p. 274). Young people who experience cultural discontinuity between home and school may perceive themselves as poor learners and may develop a negative self-concept (Souto-Manning \& Mitchell, 2010). Besides, it has long been clear that the school and the curriculum usually reproduce social class differences mainly, because they value the knowledge and skills that the dominant class holds in abundance (Fenwick, 2011).

The importance of designing a culturally responsive curriculum comes into play particularly in ethno-culturally diverse nations' teacher education programmes. This is due to the fact that teacher education has a multiplying effect, and, for relevant multiplication to take place, the prospective teachers are assumed to be introduced to the essence of multicultural education while they are still in teacher education institutions. This means that having academically qualified and professionally responsible teachers is very important to provide relevant education to a society characterised by diversity. In this regard, Gay (1986) asserts that

... professional preparation programmes should help pre-service and in-service teachers to understand the concept of multicultural education, acquire some basic cultural knowledge about ethnic pluralism, learn how to analyse their own and students' ethnic attitudes and values, and develop different methodological skills for implementing multicultural education in the classroom (p. 161).

\section{Strategies to Accommodate Multicultural Perspectives in Curricula}

Different scholars suggest different strategies to entertain ethnic pluralism and cultures in curricula in a diverse society. According to Gay (2000), educators are supposed to be diligent in ensuring that curriculum content about ethnically diverse groups is accurate, authentic and comprehensive. In addition, culturally responsive curriculum content is expected to deal with concepts, principles and ideas generalisable across 
ethnic groups and knowledge about the particular lives, experiences and contributions of specific ethnic groups. Therefore, curriculum designers are always expected to use a variety of content sources from different genres and disciplines, such as textbooks, literature, mass media, personal experiences and research findings. Similarly, Purnell, Ali, Begum and Carter (2007) state that "a culturally responsive curriculum is designed to recognize and accept the wide range of cultural differences that exist in every classroom" (p. 420).

Curriculum sources and contents that provide accurate presentations of ethnic and cultural diversity offer several benefits in improving students' achievement. First, they provide those who have never had close personal contact with members of ethnic groups other than their own with opportunities to communicate and engage with diverse people. This experience, in turn, may calm down certain fears, dispel some myths and produce learning that may not be grasped from books and other sources. This, in turn, may enhance receptivity and mastery of concepts. Second, students will actively participate in their learning as interpersonal problems will be minimised. Third, students will have real power to structure their own learning. As a result, they will have control over their own academic destinies (Gay, 2000). These overall advantages are assumed to foster better students' learning outcomes.

\section{Approaches to the Inclusion of Culture into Teacher Education Curriculum}

There are three approaches (Banks, 1986) in the selection and inclusion of culture into a teacher education curriculum: the assimilation approach, the cultural pluralism approach and the multiculturalism approach. The assimilation approach encourages the incorporation of one dominant culture into a curriculum that is expected to be adapted by the various ethnic groups of society. Supporters of this approach believe that the major goal of education for ethnic and cultural minorities is to help them to acquire the knowledge, attitudes and skills needed to participate in the mainstream society.

The cultural pluralism approach emphasises the existence of different ethnic group cultures on an equal footing. Individuals within ethnic groups all have the same basic civil rights. Society is viewed as a plurality of different groups. The identity of the individual is an extension of the identity of the group to which he/she belongs. Therefore, schools and curricula are expected to express and reinforce ethnic identities depending upon the dominant group. In short, cultural pluralism holds the view that each individual without self or group identification is given respect, dignity, freedom, and citizen rights (Stevens \& Wood, 1995).

Lastly, multiculturalism is an approach that fosters the inclusion of various ethnic group cultures into curricula and teaching materials in a fair way. The curricula would include teaching and learning about various groups' cultures as well as the shared common culture. As in society, students interact with more than one set of cultural values. Teachers take ethnic differences among students into account when selecting and applying teaching approaches and learning styles (Banks, 2006; Stevens \& Wood, 1995). This last approach is the one I adopt in this paper as it underpins the assumption guiding this research. 


\section{Approaches to the Integration of Multicultural Education into Teacher Education Curriculum}

In assessing the degree to which multicultural education is addressed in a teacher education programme, different scholars emphasise different dimensions (Gay, 1986). Nevertheless, in this paper, the four approaches to the integration of ethnic and multicultural contents into teacher education curricula suggested by Banks (1993, 2001, 2006) were used as core analytical frameworks due to the fact that they are time-tested as well as because of their wider application in the study of multicultural teacher education curricula. The four approaches are: the contributions approach, the addition approach, the transformation approach and the social action approach.

The contributions approach is mainly used when a teacher education institution attempts to integrate ethnic and multicultural contents into the mainstream teacher education curricula for the first time (Banks, 1993, 2001, 2006). It involves the incorporation of various ethnic group cultures and other forms of ethnic identities into the existing teacher education curricula as supplements. According to Banks (2006), through this approach, discrete cultural elements, such as the foods, dances, music and artifacts of ethnic groups, are studied, but little attention is given to their meanings and importance. In addition, ethnic content is limited primarily to special days, weeks and months related to ethnic events and celebrations. This approach, as Bokhorst-Heng (2007) argues, involves the 'surface culture' that does not get to the heart of cultural meanings, i.e. the 'deep culture'. In this paper, the key indicators I used with respect to this approach are assessing the extent to which the cultures as well as artifacts of, at least, the major ethnic groups of Ethiopia are incorporated as supplements to the current secondary teacher education curricula.

The addition approach deals with the insertion of ethnic contents, concepts, themes and perspectives (Banks, 1993, 2001, 2006) into the existing teacher education curriculum without changing its basic purposes and structures. According to him, this approach is often practised by the addition of a book, a unit or a course to the existing teacher education curriculum without changing it drastically. The core indicators of this approach for my research involved analysing the extent to which the objectives, contents, learning activities and modes of assessments that reflect the Ethiopian people's cultures are addressed in the secondary teacher education curricula without completely changing their basic aims, structures and frameworks.

The transformation approach emphasises changing the basic components of the existing teacher education curricula so as to enable prospective teachers to view things from several perspectives of ethic groups. According to Banks (1993, 2001, 2006), it is neither possible nor desirable to view every issue, concept, event or problem from the point of view of every ethnic group. Rather, the central goal is to enable prospective teachers to view those issues from more than one perspective. As stated by Banks (2006), in this approach, the key curriculum issues involved in a multicultural teacher education curriculum reform are the infusion of various perspectives, frames of references and contents from different groups that will extend prospective teachers' understandings of the nature, development and complexity of ethno-culturally diverse society. The key indicators used in this study regarding this approach are examining the degree to which attempts are made to change the objectives, contents, learning activities, instructional resources and assessment methods of the current secondary teacher education curricula 
of Ethiopia by infusing multi-ethnic as well as multicultural contents into them. This is assumed to make the curricula representative of the cultures of the various ethnic groups of the country, thereby encouraging prospective teachers to have in-depth understanding about the multiplicity of Ethiopian cultures from different angles.

The last approach is the social action approach. This approach emphasises competencies that require teacher candidates to make decisions and take actions based on what they studied in a given teacher education curriculum. The central intent of the teaching and learning process is to educate prospective teachers in how to analyse their social realities using appropriate decision-making skills (Banks, 1993, 2001, 2006) to enable them to take action ultimately. Furthermore, teaching and learning activities aim at empowering students to become reflective and active participants in social change. The core indicators used in this research with respect to this approach are evaluating whether contents of the current Ethiopian secondary teacher education curricula help the prospective teachers to become change agents.

To sum up, the four approaches are used as the core analytical tools to assess the extent to which the multiplicities of the cultures of the Ethiopian society are represented in the secondary teacher education curricula. Moreover, the four approaches were used to analyse whether multi-ethnic and multicultural contents are entertained in the Ethiopian secondary teacher education curricular elements, such as objectives, contents, learning activities, instructional resources and evaluations (Stark \& Lattuca, 1997), in a harmonised manner.

\section{Methodology}

This study assesses how the multi-ethnic and multicultural characteristics of the diverse Ethiopian society are incorporated into the current national secondary teacher education curricula. To that end, content analysis was used as a tool for data collection. Content analysis is an accepted method of textual investigation (Silverman, 2006). First of all, the entire national curriculum framework prepared for the current secondary teacher education programme, which consists of the descriptions/syllabi of each of the 12 professional courses, was analysed. Of all the 12 professional courses designed for the PGDT programme, the courses entitled "School and Society", "Action Research" and "Practicum" were taken as samples using a purposive sampling technique.

The three courses were selected as samples due to the fact that they are designed in a modular material form for a distance mode of delivery where basic curricular elements are presented in a detailed and explicit manner that may promote self-learning. The three courses were, therefore, found to be more suitable for conducting the content analysis process than the other courses designed for the PGDT programme since content analysis requires well-developed texts that give room for an in-depth analysis. Further, taking into consideration the dynamic nature of curricula, the entire contents of the sample texts were analysed.

As a research method, content analysis is used differently by different scholars (Krippendorff, 2004). However, in this research, regarding the quantitative content analysis, Sarantakos' (2005) model that explains content analysis as a systematic, objective and quantitative method was used. Systematic refers to categorising and applying a set of procedures to all the contents to be analysed. Objective means that it is free from personal views, and quantitative means that it is counted in terms of numbers. 
In order to pool the results for the quantitative content analysis, a coding sheet, which consists of 12 items, was prepared in the form of a Likert scale with five options (fully agree, agree, no opinion, disagree and fully disagree). The five alternatives were used to ensure relatively better flexibility in the coding of the sample texts. The coding sheet was prepared based on Banks' $(1993,2001,2006)$ four approaches to the integration of ethnic and multicultural contents into teacher education curricula. Each of the four core indicators were systematically repeated three times to check the consistency of the coders' responses. Accordingly, the first three indicators were framed based on the contributions approach whereas indicators number four, five and six were prepared in line with the addition approach. Indicators number seven, eight and nine were designed based on the transformation approach, whereas the last three indicators were set to address a social action approach (Table 1). Each item in the coding sheet was judged for its validity, whether each of the items was developed based on the respective Banks' four dimensions as well as the intelligibility of the wording, by senior researchers in the areas of higher education and curriculum studies. The four texts were coded based on the indicators presented in Table 1.

Table 1

Indicators for the Analysis of Ethnic and Multicultural Contents in Ethiopian Secondary Education Teacher Training Curricula

\begin{tabular}{ll}
\multicolumn{1}{c}{ Indicators } \\
\hline $1 \quad$ The cultures of the majority of Ethiopian ethnic groups are \\
incorporated into the objectives, contents, learning activities \\
and evaluations of the secondary education teacher training \\
curricula to supplement the core themes of the mainstream \\
curricula.
\end{tabular}


Sequel to Table 1.

\begin{tabular}{|c|c|c|c|c|c|c|}
\hline 1 & 2 & 3 & 4 & 5 & 6 & 7 \\
\hline 6 & $\begin{array}{l}\text { Concepts that reflect the Ethiopian ethnic groups' cultures } \\
\text { are added to the secondary education teacher training } \\
\text { curricula in the form of units and/or courses without } \\
\text { changing them substantially. }\end{array}$ & & & & & \\
\hline 7 & $\begin{array}{l}\text { The purposes, contents, learning activities and assessment } \\
\text { methods of the current secondary education teacher training } \\
\text { curricula are changed fundamentally so as to enable pros- } \\
\text { pective teachers to view concepts, issues and themes from } \\
\text { many ethnic groups' perspectives. }\end{array}$ & & & & & \\
\hline 8 & $\begin{array}{l}\text { The overall features (purposes, contents, sequences, learning } \\
\text { activities, instructional resources and evaluations) of the } \\
\text { secondary education teacher training curricula are com- } \\
\text { pletely changed to make them responsive to the cultures of } \\
\text { the majority of Ethiopian peoples. }\end{array}$ & & & & & \\
\hline 9 & $\begin{array}{l}\text { Contents that extend prospective teachers' cognitions of the } \\
\text { nature, development and complexity of the diverse Ethiopian } \\
\text { society are addressed in the teacher education curricula. }\end{array}$ & & & & & \\
\hline 10 & $\begin{array}{l}\text { Contents and/or learning activities that help prospective } \\
\text { teachers to become active citizens are addressed in the } \\
\text { secondary education teacher training curricula. }\end{array}$ & & & & & \\
\hline 11 & $\begin{array}{l}\text { Contents which aimed at educating prospective teachers to } \\
\text { analyse about their social realities thereby develop decision- } \\
\text { making skills are accommodated in the teacher education } \\
\text { curricula. }\end{array}$ & & & & & \\
\hline 12 & $\begin{array}{l}\text { Balance was maintained in borrowing core elements of } \\
\text { curriculum from international perspectives and in incor- } \\
\text { porating Ethiopian indigenous knowledge into the secon- } \\
\text { dary education teacher training curricula. }\end{array}$ & & & & & \\
\hline
\end{tabular}

When it comes to selection of coders, three with specialisation in curriculum studies and one with specialisation in the English language and literature were selected purposely due to the fact that all of them are teachers' educators and the relevance of their areas of specialisation to the study under consideration. Further, the person with specialisation in the English language and literature was chosen as he was found to have special training as well as awareness of multicultural education. In addition, the coders were taken from two of the Ethiopian universities with comparatively better experiences in secondary teacher education programme: two from Addis Ababa University and two from Adama Science and Technology University. They were given thorough training in how to code the sample texts. The training focused on establishing a common baseline through understanding how multicultural education is conceptualised in this study. Moreover, the training emphasised understanding the essence of the coding sheet and how to use it in analysing the sample texts through checking off the five-point Likert scale. In order to ensure the validity of the coding process, each of the sample courses was coded by two coders separately. As part of the follow-up process of the coding procedure as well as for cross-checking purposes, I participated as a co-coder for each of the four texts. 
The reliability of the coding process was checked using Sarantakos' (2005) standard, i.e. $80 \%$ as satisfactory. Thus, the two respective coders' level of agreement or the hit or miss between the coders in the respective courses was determined by comparing each of the percentage of concordance to $80 \%$. The assumption was that, if the level of agreement between the two coders was less than $80 \%$, the coding process would be considered as unreliable. If the concordance between the two coders was equal or greater than $80 \%$, it was taken to be reliable. Based on the results, how multi-ethnic and multicultural contents are addressed in the current Ethiopian secondary teacher education curricula is determined.

In addition, qualitative content analysis was employed to compare its results with the research findings obtained through the quantitative content analysis. The qualitative content analysis was made to analyse the degree to which issues of multiethnic and multicultural education are embedded in the latent contents of the sample texts. In other words, this part of the content analysis concentrated on the latent contents which are unobservable, and that should be measured indirectly (Neuendorf, 2002). Furthermore, unlike quantitative content analysis, qualitative content analysis gives the possibility to investigate words and images (Hammersley, 1990). Qualitative content analysis may also help a researcher to explore the meaning and realities beyond the words and images (Alvesson \& Skoldberg, 2009). In short, it was against the backdrop of the above discussions that the qualitative content analysis was made in relation to Banks' four approaches to the integration of ethnic and multicultural contents into teacher education curricula.

In general, in this study, both qualitative and quantitative content analyses were made to obtain valid and reliable research results. This is guided by the notion that any researcher who engages in content analysis is expected to consider both the manifest and the latent contents of the document under consideration. This is also important to triangulate the results of the content analyses.

\section{Results and Discussions}

This section deals with the results of the study and the subsequent discussions. As such, results of both the qualitative as well as the quantitative content analyses were presented and discussed. To that effect, in the case of the quantitative content analysis, since the final results of the coding process found to converge mainly to the option 'fully disagree,' the five-point scale was reduced to a three-point scale to present the results in a concise manner. To that effect, in the case of the quantitative content analysis, since the final results of the coding process found to converge mainly to the option 'fully disagree,' the five-point scale was reduced to a three-point scale to present the results in a concise manner. In so doing, the values of the options 'fully agree' and 'agree' were combined. Similarly, the values of the alternatives 'fully disagree' and 'disagree' were summed up. This resulted in having a Likert scale with three columns agree, no opinion and disagree. So, the upcoming results and discussions were made based on the three-point scale table. 


\section{Curriculum Framework for the Secondary Teacher Education Programme in Ethiopia}

This document encompasses the syllabi of all the 12 professional courses designed for the current Ethiopian secondary teacher education programme. It was developed in connection with the introduction of the PGDT programme in 2009. It consists of, amongst other things, the total number of courses to be offered, their breakdowns and descriptions.

Compared to the secondary teacher education curricula under TESO, in this curriculum framework, certain attempts are made to accommodate multicultural education in Ethiopian secondary teacher education curricula. For instance, for the first time in the history of Ethiopian teacher education, a two-credit course entitled "Teaching in a Multicultural Setting" was included as a fully-fledged course. Although this is argued to be insufficient concerning the importance of multicultural and multi-ethnic education in a diverse nation as Ethiopia, it could be considered as a positive development. Moreover, the course entitled "Inclusive Education" has been included. Because of the inclusive nature of multicultural education, one may expect that issues of multicultural and multiethnic education are to be entertained in the course "Inclusive Education". Nevertheless, the qualitative content analysis reveals that it solely dwells on the issues of special needs education.

Moreover, it is pinpointed in the general framework (Ethiopian Ministry of Education, 2009) that "the process of secondary school teacher preparation has to be guided by such value orientation as inclusiveness, caring, multiculturalism, learner-centered and pragmatism" (p. 11). In addition, it is indicated that the secondary teacher education curricular contents should be related to current societal changes, such as integrating knowledge and competencies concerned with unavoidable socio-cultural realities such as multiculturalism and teaching in minority settings (Ethiopian Ministry of Education, 2009). This shows that there is a tendency of tilting the Ethiopian secondary teacher education programme towards the diverse characteristics of the country. This, on the other hand, calls for introducing the teacher candidates to the multiple ways through which humans acquire knowledge, develop skills and attitudes to effectively cope with the multiplicities prevailing in their society and beyond. As Kolikant and Pollack (2009) state "...education can and should emphasize the multi-perspectivity, controversy, and plurality of human knowledge and thought in order to help students to understand and deal with contradictions in their world" (p. 673).

In general, the results of the qualitative content analysis of the general curriculum framework revealed that core elements of ethnic and multicultural education are, to a large extent, missing from the major parts of the document. In other words, although there are some initial ideas that indicate the importance of incorporating multicultural education into Ethiopian secondary teacher education curricula, the diverse characteristics of the Ethiopian society are, to a great extent, missing in the general curriculum framework. This was ascertained by the results of the quantitative content analysis whereby the two coders' level of agreement is $83.33 \%$. This means that, out of the 12 indicators applied, the coders came to agree on 10 of the options that showed a complete absence of ethnic and multicultural contents in the national secondary teacher education curriculum framework.

Concerning the importance of teacher education in implementing issues of diversity that are addressed both in the Ethiopian constitution and the education and training policy, one would expect multi-ethnic and multicultural education to be infused into 
each of the 12 courses designed for the PGDT programme so that each teachers' educator may synchronise issues of diversity with the contents he/she teaches. This, in turn, may help the prospective teachers to develop a better understanding of issues of ethnic pluralism and multiculturalism thereby acquainted with strategies to manage such multiplicities during the course of their education and training programme. Many scholars argue that ethnic and cultural diversity needs to be woven into all the components of a teacher education curriculum, rather than being treated only in an isolated course or in fragments scattered across the programme (Banks, 2006; Chan, 2006; Gagliardi, 1995; Gay, 2000). Besides, according to Gay (1997), multicultural assumptions, issues, contents, materials and techniques need to be infused into deliberate, systematic and substantive ways throughout the entire structure of teacher education programmes and curricula.

However, both the qualitative and the quantitative content analyses show that this is not the case in the current Ethiopian national secondary teacher education curriculum framework. Besides, particularly through the qualitative content analysis, it is found that, except for one paragraph that deals with the description of the course "Teaching in a Multicultural Setting”, issues of multi-ethnic and multicultural education are missing in the remaining 11 descriptions of the national secondary teacher education curriculum. Instead of being integrated into each professional syllabus, multicultural education is presented as a separate course with only two credits out of the total of 40 credits allocated to professional courses of the PGDT programme. This might have emanated from lack of in-depth knowledge and skill regarding how to design a general teacher education curriculum framework whereby issues of diversity are infused in each and every professional course. On the other hand, the experts who designed the general curriculum framework may deliberately overlook issues of ethno-cultural diversity thinking that incorporating such issues into the framework may not be welcomed by certain groups of society. The experts may also think that incorporating ethno-cultural perspectives into the framework could be considered as political issues.

\section{School and Society}

This module or study material has 139 pages. Its core purposes are to help prospective teachers to understand the overall school environment and the nature of society in which the school is operating analyse forms of societal participation in school affairs and comprehend the role of teachers in fostering school-community relationships. The course may bring the attention of Ethiopian secondary school prospective teachers to the social reconstruction ideology where schools are believed to serve as agents of social change. According to Kenea (2010), the social reconstruction perspectives recognise the power of the formal curricula and teachers to counter the out-of-school influences and the ultimate role of schools to build the future of society.

Fernandez, Ritchie and Barker (2008) contend that "engagement in social practice is the fundamental process by which we learn, and we become who we are" (p. 190). This may be realised if prospective teachers are trained through learning activities which involve cooperative learning, development of interpersonal relationships, appreciation of differences and intercultural grouping of students that create opportunities for them to exercise tolerance and reciprocity.

It could be argued that, for prospective teachers who are expected to work in ethno-culturally diverse nations like Ethiopia, having a clear understanding of how 
issues such as culture and ethnicity influence students' learning is extremely important. This, in turn, shows that prospective teacher education and training should highlight issues of diversity. In addition, if a teacher education curriculum is to serve societal interest, one expects it to be designed in a way that addresses the society's culture, language, history and tradition so that the prospective teachers are acquainted with knowledge, develop skills and attitudes necessary to preserve as well as sustain those important attributes in a fair way as part of teaching in multicultural settings. These overall competences may help the teacher candidates to understand diversity perspectives. This means that, rather than judging other people's cultural practices against their own, they learn to value the diverse cultural practices as valid and worthy (Souto-Manning \& Mitchell, 2010).

The qualitative content analysis revealed however that this is not the case in the course "School and Society". In other words, whereas the course "School and Society" is suitable for infusing the essence of ethnic and multicultural education into its objectives, contents, learning activities, instructional resources and modes of evaluations in a harmonised manner, issues of ethnic and multicultural education are missing. This was confirmed by the two coders' level of concordance of $91.67 \%$. This means, out of the 12 indicators, the coders agreed on 11 of them that indicated a complete absence of elements of ethnic and multicultural education. This may emanate from lack of awareness about the importance of integrating issues of diversity into the study material by the writer, and/or the writer might deliberately downplayed these issues thinking that they are sensitive topics.

This also means that if issues of multiethnic and multicultural education are missing in a course which is assumed to be more suitable for integrating them into a teacher education programme, it is less likely that those issues are incorporated into the rest of the teacher education and training courses. In addition, the absence of elements of multi-ethnic and multicultural education in the course entitled "School and Society" may imply that what is being taught under the auspices of the Ethiopian secondary teacher education programme is not reflective of the diversity that characterises the Ethiopian society.

\section{Action Research}

This study material has 73 pages in total and consists of two parts. Part one is organised into three units. Unit one deals with the basics of action research, such as its conceptions, importance and characteristics. The second unit dwells on the processes of action research which involve planning, acting, developing and reflecting. The third unit emphasises the preparation and presentation of an action research project report. In all of the three units, pre-reading activities, unit objectives, contents and summaries are provided.

The qualitative content analysis showed that multiethnic and multicultural education are not addressed in any form of Banks' $(1993,2001,2006)$ four approaches of treating ethno-cultural contents in a teacher education curriculum. Here, it could be argued that "Action Research" as a professional course could be a potential subject through which prospective teachers would practically acquire the fundamental knowledge, skills and attitudes necessary for managing issues of diversity by engaging in practical and solutionoriented small-scale research activities individually and/or in teams. In support of this 
argument, Souto-Manning and Mitchell (2010) assert that to make classrooms more inclusive and culturally-responsive, action research, especially collaborative action research, could be a critical tool for gathering invisible and multi-faceted knowledge that researchers as outsiders and teachers as insiders cannot solely record and/or obtain. Moreover, Chan (2006) claims that "given the role of experience in shaping perceptions of curriculum, we can expect that teachers' practices and beliefs about incorporating culture into the curriculum would be shaped by their own experiences of culture in their school curriculum” (p. 172).

However, the results of the qualitative content analysis showed that elements of ethnic and multicultural education are not incorporated into any part of the study material. This argument was confirmed by the result of the quantitative content analysis where the two coders' level of agreement was $100 \%$, indicating the complete absence of issues of multicultural education. This might result from the course writer's unawareness about the relevance of addressing issues of diversity that await the prospective teachers after graduation and/or it might be due to resistance. This may also emanate from the Ethiopian Ministry of Education's lack of awareness or concern about the importance of incorporating basic elements of multicultural education in each professional course as important tool for implementing the objectives stated in the Ethiopian education and training policy and in the general secondary teacher education curriculum framework in relation to issues of diversity.

\section{Practicum}

This study material has 108 pages and is grouped into three subsequent sections: practicum I, practicum II and practicum III. According to the course, Ethiopian secondary education prospective teachers are expected to engage in reflection upon what they are learning in the other professional courses in light of the actual teaching practices in the nearby secondary schools. This requires the teacher candidates to observe and practise teaching in the schools throughout the education and training programme. Accordingly, from the very beginning, prospective teachers will go to the nearby partner secondary schools on a regular basis and conduct critical observations, do assignments related to each professional course and gradually practise teaching.

As stated earlier, according to the PGDT programme, Ethiopian secondary teacher education is conducted for one year, although, in actual terms, the training lasts for ten months. This training is divided into three terms of three months' duration (Ministry of Education, 2009). Each term is assumed to help prospective teachers to maintain the sequence and integration of the courses into the whole secondary teacher preparation programme. According to this arrangement, prospective teachers can take basic courses well ahead of those courses which deal with the specifics of teaching. In addition, those courses that complement each other are offered in the same term. $30 \%$ of the courses given in the first two terms are school-based activities. Each prospective teacher taking those courses is required to do school-based assignments by actually experiencing the different aspects of teaching in the schools (Ethiopian Ministry of Education, 2009). This means that, in these two terms, practicum is conducted along with each professional course offered in the two terms. In the third term, the prospective teacher is assumed to work independently with little support from the mentor. 
As can be seen from the way the practicum is structured, it could be argued that basic elements of ethnic and multicultural education could be infused into the entire practicum programme so that integration within the course itself as well as across the other professional courses could easily be maintained. Nevertheless, the results of the qualitative content analysis revealed that fundamental elements of multicultural education are missing in the course. This is also supported by the two coders' concordance of $100 \%$, indicating a complete absence of ethnic and multicultural education contents.

According to Zeichner (1992), prospective teachers' placement in schools in relation to practicum could involve commitment to the preparation of teachers to serve students of all social and cultural backgrounds. As argued by him, the old model of the practicum was based on a view of teaching as an applied science; the prospective teacher's role was to apply what had been learned in a teacher education institution to actual teaching in schools. Nevertheless, the new practicum involves recognition that learning to teach is a process that continues throughout a teacher's professional career and that no matter what we do in our teacher education programmes and no matter how well we do it, at best, we can only prepare prospective teachers to begin teaching. Consequently, teacher educators must help prospective teachers to take responsibility for their own professional development. One could, therefore, claim that Ethiopian secondary education practicum programme is not preparing the prospective teachers for the type of school environment awaiting them.

\section{Conclusions}

Multi-ethnic and multicultural education issues are high on the agenda worldwide, especially in the teacher education system of countries characterised by diversity. Nevertheless, although Ethiopia can be characterised as a mosaic consisting of well over 80 ethnic as well as linguistic groups, basic elements of multicultural education, such as ethnicity and culture are, to a large extent, missing in the overall teacher education system of the country. Core elements of multi-ethnic and multicultural education are also missing in the secondary teacher education curriculum framework and the specific courses designed based on the general curriculum framework. Due to this, there is a very limited degree of vertical integration between the national secondary teacher education curriculum framework and the specific secondary teacher training courses regarding the incorporation of basic elements of multi-ethnic and multicultural education into the secondary teacher education curricula. In addition, neither the national curriculum framework nor the specific sample professional courses reflect the Ethiopian ethnic group cultures.

In other words, even though there are certain initial ideas that are useful to gear the Ethiopian secondary teacher education programme towards multiculturalism in the general national curriculum framework, these have not been repeated in the development of the three sample professional courses. On the basis of these findings, one could argue that it is necessary to incorporate basic components of multi-ethnic and multicultural education into the general national curriculum framework and the specific professional courses in an integrated manner so that they could reinforce each other in a positive way in equipping the prospective teachers with the cultural competence necessary for teaching in a multicultural setting. Moreover, while attempting to do justice to all the cultures of the nations and nationalities of Ethiopia, for the sake of manageability, it is important to incorporate the cultures of at least the major ethnic groups, namely Oromo, 
Amhara, Somali, Tigraway, Sidama who constitute $34.5 \%, 26.9 \%, 6.2 \%, 6.1 \%$ and $4.0 \%$ of the total population respectively (Federal Democratic Republic of Ethiopia Population Census Commission, 2008) into the entire secondary teacher education curricula. This would include both the national curriculum framework and the specific professional courses to help the prospective teachers to gain different perspectives.

In so doing, amongst other things, the knowledge, skills and attitudes of the people that involve in the development of the teacher education curricula are expected to be improved with respect to multi-ethnic and multicultural education. To this end, the Ethiopian Ministry of Education is expected to provide courses that focus on how to infuse issues of multiethnic, multicultural and multilingual education into the entire secondary teacher education curricula to the experts who are in charge of developing the curricula. In addition, it is important to make sure that those courses help the experts to bring real attitudinal changes concerning the issues of diversity through challenging their deep-seated preconceived attitudes.

Moreover, it is necessary for the Ethiopian Ministry of Education to develop a clear guideline which indicates how to design teacher education curricula via balancing cultural diversity and national unity, indigenous knowledge and international knowledge, and the likes. Moreover, it is of relevance that the guideline indicates how to effectively apply ethno-culturally sensitive teaching strategies and assessment techniques in a teacher education programme. Furthermore, it is necessary that the Ethiopian Ministry of Education makes sure that the experts who design the secondary teacher education curricula are representatives of, at least, the major ethnic groups outlined above. This representation is important, amongst other things, to get specific cultural contents and inputs which are assumed to be incorporated into the curricula from the various ethnocultural groups of the country.

\section{Acknowledgement}

I would like to thank all those who have provided constructive suggestions and support for this paper, in particular Professor Lene Buchert, Professor Berit Karseth, Professor Peter Maassen, Professor Karen Jensen, Professor Andreas Lund, Professor Bjorn Stensaker and Martina Vukasovic. I also thank colleagues who helped me to code the sample texts.

\section{References}

Alvesson, M., \& Skoldberg, K. (2009). Reflexive methodology: New vistas in qualitative research ( $2^{\text {nd }}$ ed.). London: Sage Publications Ltd.

Apple, M. W., \& Christian-Smith, L. K. (1991). The politics of the textbook. In M. W. Apple \& L. K. Christian-Smith (Eds.), The politics of the textbook (pp. 121). New York: Routledge.

Banks, J. A. (1986). Race, ethnicity, and schooling in the United States: Past, present and future. In J. A. Banks \& J. Lynch (Eds.), Multicultural education in western societies (pp. 29-50). New York: Holt, Rinehart and Winston Ltd.

Banks, J. A. (1993). Approaches to multicultural curriculum reforms (2 $2^{\text {nd }}$ ed.). In J. A. Banks \& C. A. M. Banks (Eds.), Multicultural education: Issues and perspectives (pp. 195-214). Boston: Allyn and Bacon. 
Banks, J. A. (2001). Multicultural education: Characteristics and goals ( $3^{\text {rd }}$ ed.). In J. A. Banks \& C. A. M. Banks (Eds.), Multicultural education: Issues and perspectives (pp.1-31). Boston: Allyn and Bacon.

Banks, J. A. (2006). Multicultural education and knowledge construction. In J. A. Banks (Ed.), Race, culture, and education: The selected works of James A. Banks (pp. 127164). London: Routledge.

Banks, J. A. (2010). Multicultural education: Characteristics and goals ( $7^{\text {th }}$ ed.). In J. A. Banks \& C. A. M. Banks (Eds.), Multicultural education: Issues and perspectives (pp. 3-32). Hoboken: John Wiley and Sons, Inc.

Bokhorst-Heng, W. D. (2007). Multiculturalism's narratives in Singapore and Canada: Exploring a model for comparative multiculturalism and multicultural education. Journal of Curriculum Studies, 39(6), 629-658.

Bowen, J. D. (1976). Teacher training and problems of staffing the schools. In M. L. Bender, J. D. Bowen, R. L. Cooper \& C. A. Ferguson (Eds.), Language in Ethiopia (pp. 461-481). London: Oxford University Press.

Bruner, J. (1996). The culture of education. Cambridge: Harvard University Press.

Chan, E. (2006). Teacher experiences of culture in the curriculum. Journal of Curriculum Studies, 39(2), 161-176.

Chan, E. (2007). Student experiences of a culturally-sensitive curriculum: Ethnic identity development amid conflicting stories to live by. Journal of Curriculum Studies, 39(2), 177-194.

Egne, R. M. (2010). Washback effects of handouts on the teaching and learning process in the higher education institutions in Ethiopia: Adama University in focus. Journal of Teacher education for Sustainability, 12(2), 130-142.

Ethiopian Ministry of Education. (2003).Teacher education system overhaul handbook. Addis Ababa: Ethiopian Ministry of Education.

Ethiopian Ministry of Education. (2009). Postgraduate diploma in teaching: Curriculum framework for secondary school teacher education programme in Ethiopia. Addis Ababa: Ethiopian Ministry of Education.

Federal Democratic Republic Government of Ethiopia. (1994). Education and training policy. Addis Ababa: Berhanena Selam Printing Enterprise.

Federal Democratic Republic of Ethiopia. (1995). The constitution of the Federal Democratic Republic of Ethiopia. Addis Ababa: Berhanena Selam Printing Enterprise.

Federal Democratic Republic of Ethiopia Population Census Commission. (2008). Summary and statistical report of the 2007 population and housing census: Population size by age and sex. Retrieved March 11, 2013, from http://www.csa.gov.et/ pdf/Cen2007_firstdraft.pdf

Fenwick, L. (2011). Curriculum reform and reproducing inequality in upper-secondary education. Journal of Curriculum Studies, 43(6), 697-716.

Fernandez, T., Ritchie, G., \& Barker, M. (2008). A sociocultural analysis of mandated curriculum change: The implementation of a new senior physics curriculum in New Zealand schools. Journal of Curriculum Studies, 40(2), 187-213.

Gagliardi, R. (1995). An integrated model for teacher training in a multicultural context. In R. Gagliardi (Ed.), Studies in comparative education: Teacher training and multiculturalism (pp. 1-13). UNESCO: International Bureau of Education.

Garcia, J., \& Pugh, S. L. (1992). Multicultural education in teacher preparation programs: A political or an educational concept? Phi Delta Kappa, 74(3), 214-219. 
Gay, G. (1986). Multicultural teacher education. In J. A. Banks \& J. Lynch (Eds.), Multicultural education in western societies (pp. 154-177). New York: Holt, Rinehart \& Winston Ltd.

Gay, G. (1997). Multicultural infusion in teacher education: Foundations and applications. Peabody Journal of Education, 72(1), 150-177.

Gay, G. (2000). Culturally responsive teaching: Theory, research, and practice. New York: Teachers College Press.

Goodson, I. F. (1988). The making of the curriculum: Collected essays. London: The Falmer Press.

Hammersley, M. (1990). Classroom ethnography: Empirical and methodological essays. Milton Keynes: Open University Press.

Harber, C. (1994). Ethnicity and education for democracy in Sub-Saharan Africa. International Journal of Educational Development, 14(3), 255-264.

Hussein, J. W. (2006). Locating the value conflicts between the rhetoric and practices of the public and teacher education in Ethiopia within the hegemony of the global neoliberalism and seeking the alternative in critical pedagogy. Journal of Critical Education Policy Studies, 4(2), 1-8.

Hussein, J. W. (2008). The politics of language, power, and pedagogy in Ethiopia: Addressing the past and present conditions of the Oromo language. Australian Journal of Linguistics, 28(3), 31-57.

Karseth, B. (2004). Curriculum changes and moral issues in nursing education. Nurse Education Today, 24(8), 638-643.

Kenea, A. (2010). Education and diversity: Pupils' perceptions of 'others' and curricular responses at selected sites in Ethiopia. The Ethiopian Journal of Education, 30(1), $23-50$.

Kolikant, Y. B., \& Pollack, S. (2009). The asymmetrical influence of identity: A triadic interaction among Israeli Jews, Israeli Arabs, and historical texts. Journal of Curriculum Studies, 41(5), 651-677.

Krippendorff, K. (2004). Content analysis: An introduction to its methodology (2nd ed.). Thousand Oaks: Sage Publications.

Masemann, V. L. (2007). Culture and education ( $3^{\text {rd }}$ ed.). In R. F. Arnove \& C. A. Torres (Eds.), Comparative education: The dialectic of the global and the local (pp. 101116). Lanham: Rowman \& Littlefield Publishers, Inc.

Mergo, B. (2006). Assessment of the contributions of Madda Walabu University to the Regional State of Oromiya. The Ethiopian Journal of Higher Education, 3(1), 133152.

Mergo, B. (2008). Retrospects and prospects of multicultural teacher education in the higher education institutions of Ethiopia: Adama University in Focus. The Ethiopian Journal of Education, 28(2), 73-100.

Mergo, B. (2010). Obstacles in job creation and employment for TVET graduates in Ethiopia: The case of Oromiya Regional State. The Ethiopian Journal of Science and Sustainable Development, 1(1), 57-62.

Negash, T. (1990). The crisis of Ethiopian education: Some implications for nationbuilding. Uppsala: Uppsala University Press.

Negash, T. (1996). Rethinking education in Ethiopia. Uppsala: Nordiska Afrikainstitutet. Neuendorf, K. A. (2002). The content analysis guidebook. Thousand Oaks: Sage Publications Ltd. 
Purnell, P. G., Ali, P., Begum, N., \& Carter, M. (2007). Windows, bridges and mirrors: Building culturally responsive early childhood classrooms through the integration of literacy and the arts. Early Childhood Education Journal, 34(4), 251-258.

Sarantakos, S. (2005). Social research (3 ${ }^{\text {rd }}$ ed.). New York: Palgrave Macmillan.

Schofield, J. W. (2010). The colorblind perspective in school: Causes and consequences ( $7^{\text {th }}$ ed.). In J. A. Banks \& C. A. M. Banks (Eds.), Multicultural education: Issues and perspectives (pp. 259-283).USA: John Wiley \& Sons, Inc.

Semela, T. (2012). Intergroup relations among the Ethiopian youth: Effects of ethnicity, language, and religious background. Journal of Developing Societies, 28(3), 323354.

Semela, T. (2014). Teacher preparation in Ethiopia: A critical analysis of reforms. Cambridge Journal of Education, 44(1), 113-145.

Semela, T., Bohl, T., \& Kleinknecht, M. (2013). Civic education in Ethiopian schools: Adopted paradigms, instructional technology, and democratic citizenship in a multicultural context. International Journal of Educational Development, 33(2), 156-164.

Serbessa, D. D. (2006). Tension between traditional and modern teaching-learning approaches in Ethiopian primary schools. Journal of International Cooperation in Education, 9(1), 123-140.

Silverman, D. (2006). Interpreting qualitative data ( $3^{\text {rd }}$ ed.). Los Angeles: Sage Publications Ltd.

Sleeter, C. (2008). Equity, democracy, and neoliberal assaults on teacher education. Teaching and Teacher education: An International Journal of Research and Study, 24(8), 1947-1957.

Souto-Manning, M., \& Mitchell, C. H. (2010). The role of action research in fostering culturally-responsive practices in a preschool classroom. Early Childhood Education Journal, 37(6), 269-277.

Stark, J. S., \& Lattuca, L. R. (1997). Shaping the college curriculum: Academic plans in action. Boston: Allyn \& Bacon.

Stevens, E., \& Wood, G. H. (1995). Justice, ideology, and education: An introduction to the social foundations of education ( $3^{\text {rd }}$ ed.). New York: McGraw-Hill, Inc.

Wagaw, T. G. (1979). Education in Ethiopia: Prospect and retrospect. Ann Arbor: University of Michigan Press.

Wagaw, T. G. (1981). Emerging issues of Ethiopian nationalities: Cohesion or disintegration. Northeast African Studies, 3(1), 69-75.

Wagaw, T. G. (1999). Conflict of ethnic identity and the language of education policy in contemporary Ethiopia. Northeast African Studies, 6(3), 75-88.

Zeichner, K. (1992). Rethinking the practicum in the professional development school partnership. Journal of Teacher education, 43(4), 296-307.

Correspondence concerning this paper should be addressed Robsan Margo Egne, Assistant Professor at Adama Science and Technology University, Ethiopia and a PDD candidate at the University of Oslo, Department of Education, Sem Salands vei 7, Helga Eng's building, $5^{\text {th }}$ floor, P. O. Box: 1092 Blindern, NO-0317 Oslo, Norway. Email: r.m.egne@iped.uio.no; robsanmargo@gmail.com 